\title{
A Educação Ambiental nos anos Iniciais do Ensino Fundamental
}

\author{
Elaine Cristina da Silva Viana ${ }^{l}$; Geraldo Martins de Oliveira Júnior ${ }^{2}$; \\ Elayne Cristina Luz Menezes Novaes Cecílio Sobral ${ }^{3}$; Stevens Emanuel Cecílio Sobral ${ }^{4}$; \\ Otoniel Moreira Leite Lima
}

\begin{abstract}
Resumo: A Educação Ambiental exerce um papel importantíssimo na contemporaneidade, uma vez que as ações ao meio ambiente, principalmente as antrópicas, tem aumentado consideravelmente no decorrer dos anos. Este trabalho objetivou analisar o ensino da Educação Ambiental em uma instituição, especificamente no fundamental. A metodologia utilizada foi qualitativa. Os dados foram coletados através de entrevista semiestruturada realizada com discentes que cursam $6^{\circ}$ e $7^{\circ}$ ano, totalizando 50 entrevistados. Todos alunos da escola Municipal Francisco Filgueira Sampaio, em Serrita, Pernambuco. Os resultados demonstraram que os discentes conhecem o conceito de Educação Ambiental, e compreendem que grande parte das ações causadas à natureza partem do homem. Verificou-se que a educação ambiental é trabalhada principalmente nas disciplinas de Ciências e Geografias (55\% e 40\%, respectivamente). Quanto ao interesse por assuntos relacionados ao Meio Ambiente, 52\% tem interesse razoável. Os entrevistados apontaram a necessidade de mais trabalhos relacionados a temática. Constatou-se que a Educação Ambiental é consideravelmente trabalhada com os discentes, porém o interesse pelo assunto ainda é razoavelmente considerado, visto que a metodologia aplicada não estimula-os a prática de ações intervencionistas diretas no meio ambiente, considerando a realidade em que vivem.
\end{abstract}

Palavras-chave: Meio Ambiente, Entrevista e Ensino.

\section{Environmental Education in the Early Years of Elementary Education}

\begin{abstract}
Environmental Education plays a very important role in contemporary times, since actions to the environment, especially the anthropic ones, have increased considerably over the years. In this way, this work aimed to analyze the teaching of Environmental Education in an institution, specifically in the fundamental. The methodology used in this work was through a semistructured interview conducted with students who study 6th and 7th grade, totaling 50 interviewees, this one was developed at the Municipal School Francisco Filgueira Sampaio, in the city of Serrita, Pernambuco. From the results obtained with the interview, it was verified that the students know the concept of Environmental Education, in the same way that they understand that a great part of the actions caused to the nature depart from the man. It was verified that the environmental education is worked mainly in the disciplines of Sciences and Geographies (55\% and 40\%, respectively). When analyzing the interest of the interviewees for the subjects related to the Environment, it was verified that $52 \%$ has a reasonable interest, in this way, some interviewees indicate that more work related to the theme should be developed. Therefore, it was verified that the Environmental Education is considerably worked with the students related to the present research, however the interest for the subject is still considered reasonable, since the applied methodology does not stimulate them to practice actions in the environment, the reality in who live.
\end{abstract}

Key words: Environment, Interview and Teaching.

\footnotetext{
${ }^{1}$ Graduada em Ciências Biológicas pela Faculdade de Ciências Humanas do Sertão Central - FACHUSC, Salgueiro - PE. elainecristina.viana@bol.com.br

${ }^{2}$ Graduação em Ciências biológicas. Faculdade de Ciências Humanas do Sertão Central - FACHUSC, Salgueiro - PE.

${ }^{3}$ Graduação em Enfermagem. Faculdade Estácio, Recife - PE.

${ }^{4}$ Farmacêutico pela Uninassau. Contato: stevens_emanuel@ hotmail.com;

${ }^{5}$ Mestrado em Ciências da Educação pelo Instituto Superior de Educação Professora Lúcia Dantas. Docente da Prefeitura Municipal de Juazeiro do Norte.otonielml@ hotmail.com.
} 


\section{Introdução}

O ser humano vem utilizando os recursos naturais de forma inadequada, levando a muitas consequências, sobretudo para o meio ambiente que cada vez mais, vem sendo degradado, onde o homem tem mirado apenas no lucro em detrimento na degradação ambiental. Diante dessa situação, se faz necessária uma Educação Ambiental, que oriente as pessoas em relação ao mundo em que vivem para que possam ter acesso a uma melhor qualidade de vida, mas sem desrespeitar o meio ambiente, tentando estabelecer o equilíbrio entre o homem e o meio (MEDEIROS et al., 2011).

Outrossim, a Educação Ambiental pode ser definida como processo que consiste em propiciar aos indivíduos uma compreensão crítica e global do ambiente, para esclarecer valores e desenvolver atitudes que lhes permitam adotar uma posição consciente e participativa a respeito das questões relacionadas com a conservação e a adequada utilização dos recursos naturais (MEDINA, 1998).

No Brasil, ela assume uma perspectiva mais abrangente, não restringindo seu olhar apenas à proteção e ao uso sustentável da natureza, mas incorporando fortemente uma proposta de construção de sociedades sustentáveis. Destarte, um dos principais objetivos da Educação Ambiental é tentar despertar, em todos, a consciência de que o ser humano é parte integrante do meio ambiente (CRUZ, 2011).

Entende-se que a Educação Ambiental é um processo pelo qual o educando começa a obter conhecimentos acerca das questões ambientais presentes no meio o qual ele faz parte, onde passa a ter uma boa visão sobre o meio ambiente, sendo um agente transformador em relação à conservação ambiental (MEDEIROS et al., 2011).

Assim, neste estudo objetivou-se analisar o ensino da Educação Ambiental em uma instituição de ensino fundamental do $6^{\circ}$ ao $9^{\circ}$ ano, a partir da percepção dos discentes, tendo em vista que neste nível os educandos são bastante curiosos e abertos ao conhecimento. 


\section{Referencial Teórico}

\section{Fundamentos da Educação Ambiental}

A Educação Ambiental é considerada, inicialmente, como uma preocupação dos movimentos ecológicos com a prática de conscientização, que seja capaz de chamar a atenção para a má distribuição do acesso aos recursos naturais, assim como ao seu esgotamento, e envolver os cidadãos em ações sociais ambientalmente adequadas (CARVALHO, 2006).

De acordo com Morales (2009), a Educação Ambiental, em um contexto global, afirma e reafirma a urgência de se considerarem as diversas dimensões do conhecimento e se torna perceptível a abordagem interdisciplinar e sistêmica que impera nesse novo saber ambiental.

Desta forma, ela vem se tornando a principal responsável pelos projetos e iniciativas tomadas para evitar o consumo desenfreado dos recursos hídricos, bem como dos recursos naturais utilizados diariamente. Destarte, tudo que faz-se tem efeitos locais, nacionais e globais, uma vez que todos os ecossistemas estão interligados, Assim sendo, a Educação Ambiental assume seu papel no enfrentamento do caos ambiental, reafirmando seu compromisso rumo a mudanças comportamentais e atitudinais na construção do sujeito ecológico (BARBOSA, 2016).

No Brasil, a Lei de $n^{\circ} .9 .795$, de 27 de abril de 1999 instituiu a Política Nacional de Educação Ambiental e estabeleceu que:

Art. $2^{\circ}$ - A Educação Ambiental é um componente essencial e permanente da educação nacional, devendo estar presente, de forma articulada, em todos os níveis e modalidades do processo educativo, em caráter formal e não-formal (CRUZ, 2011).

A citada lei ainda destaca em seu artigo $1^{\circ}$ :

Entendem-se por educação ambiental os processos por meio dos quais o indivíduo e a coletividade constroem valores sociais, conhecimentos, habilidades, atitudes e competências voltadas para a conservação do meio ambiente, bem de uso comum do povo, essencial à sadia qualidade de vida e sua sustentabilidade (BRASIL, 1999).

Entretanto, antes dessa lei a Constituição Federal de 1988 já tratava do assunto, destacando em seu artigo 225:

Todos têm direito ao meio ambiente ecologicamente equilibrado, bem de uso comum do povo e essencial à sadia qualidade de vida, impondo-se ao Poder Público e à 
coletividade o dever de defendê-lo e preservá-lo para as presentes e futuras gerações (BRASIL, 1988).

Dessa forma, para coordenar a Política Nacional de Educação Ambiental (PNEA), foi criado o Órgão Gestor, dirigido pelos Ministérios do Meio Ambiente e da Educação, que implementam programas e projetos no âmbito do Programa Nacional de Educação Ambiental (ProNEA), objetivando a estruturação de um sistema nacional de Educação Ambiental integrado e descentralizado, que fortaleça os Sistemas Nacionais do Meio Ambiente e da Educação, articulando-os a outros sistemas, como o de Unidades de Conservação, de Gerenciamento de Recursos Hídricos e outros que se relacionem com a questão ambiental e a educacional (BRASIL, 2001).

Segundo Jacobi; Tristão; Franco (2009), as ações educativas ambientalmente sustentáveis nos direcionam para propostas pedagógicas centradas na criticidade e na emancipação dos sujeitos, enfatizando à mudança de comportamento e atitudes, ao desenvolvimento da organização social e da participação coletiva.

Assim, ao abordar esse tema no contexto escolar, impõe-se abrir espaço para se falar, principalmente, na importância da educação como um todo, na formação do cidadão (FONSECA; COSTA; COSTA, 2005).

Posto isto, Carvalho (2006) ressalta que a Educação Ambiental deve ser acima de tudo um ato político voltado para a transformação social, capaz de transformar valores e atitudes, construindo novos hábitos e conhecimentos, defendendo uma nova ética, que sensibiliza e conscientiza na formação da relação integrada do ser humano, da sociedade e da natureza, aspirando ao equilíbrio local e global, como forma de melhorar a qualidade de todos os níveis de vida.

\section{A Educação Ambiental nas Instituições de Ensino}

A educação constitui-se na mais poderosa de todas as ferramentas de intervenção no mundo para a construção de novos conceitos e consequente mudança de hábitos. É também mecanismo de construção do conhecimento e a forma com que todo o desenvolvimento intelectual conquistado é passado de uma geração a outra (CHALITA, 2002). 
Dessa maneira, considera-se a necessidade de compreender a Educação Ambiental como um processo de apropriação crítica de conhecimentos, atitudes, comportamentos, ideias, valores, habilidades e hábitos na construção coletiva e participativa da relação responsável da sociedade com o ambiente e também a sua importância na escola. Entre as complexas e variadas dimensões do processo de formação desses educadores, relacionadas diretamente aos complexos e diversificados elementos do processo pedagógico, está o acesso dos professores ao conjunto de saberes necessários à sua prática educativa cotidiana (REIS et al., 2012).

No entanto os processos educativos dentro da escola, os referenciais da aprendizagem social se inserem nas práticas socioambientais educativas de caráter colaborativo, que têm se revelado como veículo importante na construção de uma nova cultura de diálogo e participação (ARNSTEIN, 2002).

É importante também, que se inicie nos primeiros anos de escolaridade o ensino da Educação Ambiental, uma vez que é nesse período que começa o processo de formação da personalidade e o despertar para a cidadania, havendo a formação de cidadãos que se preocupam com o meio ambiente, Igualmente para que haja um mundo justo e equilibrado, é necessário existir uma interação entre educadores e educandos visando as transformações nas formas de se utilizarem os recursos disponíveis na natureza sem que haja agressões e que esses recursos possam estar sempre disponíveis no futuro (MEDEIROS et al., 2011).

Nesse viés, a relação entre meio ambiente e educação assume um papel cada vez mais desafiador numa sociedade carente de novos saberes para transformar o patamar atual em que se encontra a crise ambiental. Os programas educativos relacionados com a conscientização ecológica demandam enfoques integradores de uma realidade conflitante e geradora de disparidade que transcendem a mera aplicação dos conhecimentos científicos e tecnológicos disponíveis (JACOBI, 2005).

Segundo Cardoso (2011), trabalhar com Educação Ambiental nas instituições de ensino é muito importante, visto que esta permite ao aluno perceber-se enquanto parte do meio ambiente, assim como, possibilitar meios para o desenvolvimento de uma educação voltada para a cidadania consolidando o conceito de que ele deve atuar enquanto sujeito nesse meio, fortalecendo a sociedade como um todo e não enquanto parte isolada e fragmentada, uma vez que cada indivíduo deve ser entendido enquanto responsável pela defesa da qualidade de vida. 


\section{Os Desafios da Educação Ambiental nas Escolas}

Segundo Farnesi (1999), a maioria dos professores do ensino fundamental não é considera preparada para atuar como educadores ambientais e justifica, que esse tema não foi abordado durante a sua graduação ou na sua formação como um todo, com isso, as atividades de Educação Ambiental não são aplicadas no cotidiano do ensino formal, mas ocorre oportunamente ou em datas referentes ao meio ambiente, demonstrando assim que ela, está ainda ausente da vida diária das escolas.

A preparação da escola e de educadores ambientais para uma ação decisiva nos diversos níveis do ensino vai muito além das iniciativas de capacitações introdutórias sobre o tema, pois precisa permear-se no dia-a-dia de professores e alunos, e dessa maneira, o papel do professor é fundamental, e a sua atuação vai depender da preparação e conhecimento desses em lidar com a formação de atitudes e consciência, trabalhando o ensino e aprendizagem (BARCELOS, 1996).

Além disso, Andrade (2000) afirma que existem outros impedimentos que podem dificultar a inclusão da temática ambiental na escola, onde destaca vários fatores como o tamanho da escola, número de alunos e de professores, predisposição destes professores em passar por um processo de formação continuada e vontade da direção de realmente implementar um projeto ambiental que vá alterar a rotina na escola. Esses fatores somados podem dificultar ainda mais a integração da temática ambiental na educação formal.

Assim, a Educação Ambiental deve estar voltada à aprendizagem de como gerenciar e melhorar as relações entre a sociedade humana e o ambiente, de modo integrado e sustentável. Não substitui ou ultrapassa as disciplinas acadêmicas e escolares, mas deve ser aplicada a todas elas (BRASIL, 1997).

Jardim (2009) destaca que, primordialmente, precisa-se ter mais clareza sobre qual o papel político da Educação Ambiental, para que a ela possa colaborar na construção de uma proposta educacional que objetive preparar os cidadãos para exigir uma justiça social e desenvolver a autogestão e a ética nas relações sociais e com a natureza. 


\section{Material E Métodos}

\section{Área de Estudo}

O trabalho foi realizado no Município de Serrita - Pernambuco, que está localizado no Sertão Pernambucano, pertence à microrregião de Salgueiro, com uma área de $1.664 \mathrm{~km}^{2}$, distante a 544 km da capital estadual Recife. Apresenta uma população de 18.331 habitantes, com uma densidade demográfica de $12,1 \mathrm{hab} / \mathrm{km}^{2}$ (IBGE, 2010).

A área foco deste trabalho onde realizou-se as entrevistas, foi a Escola Municipal Francisco Filgueira Sampaio. A mesma funciona em dois turnos (manhã e noite), contendo aproximadamente 857 alunos.

\section{Método}

O presente trabalho foi realizado a partir de uma entrevista semiestruturada (Apêndice A), tendo como público alvo alunos de uma instituição de Ensino Fundamental do $6^{\circ}$ ao 9 ano, os quais cursam o $6^{\circ}$ e $7^{\circ}$ ano, sendo que no total foram entrevistados 50 alunos. Destarte, na entrevista foram abordadas perguntas relacionadas ao ensino da Educação Ambiental na escola, assim como a percepção desses estudantes sobre a temática, destacando o seu papel, projetos desenvolvidos, disciplinas envolvidas, etc. A pesquisa foi feita nos meses de Maio e Junho de 2018.

De acordo Britto-Júnior; Feres-Júnior (2011), algumas das principais vantagens em se utilizar a entrevista semiestruturada, estão na sua rapidez e no fato de não exigirem exaustiva preparação dos pesquisadores, o que implica em custos relativamente baixos. Outra vantagem é possibilitar a análise estatística dos dados, mesmo as respostas obtidas não sendo padronizadas, mas isto ocasiona em contrapartida, na não possibilidade de análise dos dados com uma maior profundidade. 


\section{Resultados e Discussão}

\section{A Percepção dos Discentes sobre a Educação Ambiental na Escola}

A partir dos dados obtidos na entrevista semiestrutura, constatou-se que $60 \%$ dos alunos residem na zona urbana. E em relação ao sexo dos entrevistados verificou-se que 56\% afirmaram ser do sexo masculino, não havendo uma diferença significativa nesse item.

Ao verificar a idade dos entrevistados destaca-se que 76\% apresentaram 12 anos, 20\% apresentavam 13 anos e 4\% apresentam 14 anos de idade. De acordo com Medeiros et al. (2011), é importante ressaltar as crianças porque, estas estão em fase de desenvolvimento, a qual é a melhor idade para se aprender, destacando ainda que quando "inocentes" torna-se mais fácil moldar-se novos conhecimentos, pelo contrário, os adultos já possuem hábitos e comportamentos cristalizados e de difícil reorientação.

Tendo em vista as informações coletadas identificou-se que a totalidade dos estudantes afirmaram saber o que é Educação Ambiental. O que vai ao encontro do mencionado por Guimarães (2000) o qual afirma que ela está sendo mais divulgada na mídia e entre os movimentos sociais. Ademais, foram criados programas governamentais e não governamentais de capacitação de educadores, direcionados para as questões ambientais. Nas escolas há uma maior preocupação em relação a abordagem da Educação Ambiental, e o tema vem sendo progressivamente inserido nas grades curriculares dos cursos de graduação e pós-graduação.

Em consonância com trabalhos realizados por Cardoso (2011) em uma escola localizada em Brasília, verificou-se que os alunos possuem noções sobre o que é a educação ambiental, uma vez que já ouviram falar de tal assunto em livros, revistas ou através da mídia, contudo não sabem compreender o seu significado de forma cientifica. Sendo assim para que o aluno compreenda tal conceito é necessário que o professor desenvolva metodologias adequadas para trabalhar este conceito em sala de aula, propiciando ao aluno compreender que o desenvolvimento sustentável atua enquanto meio para minimizar o uso exagerado de bens de consumo através do desenvolvimento de uma visão crítica.

Todos os discentes afirmaram que geralmente são desenvolvidos trabalhos em sala sobre a temática da Educação Ambiental. Corroborando com Lima (2004), o qual destaca que a escola é um espaço privilegiado para estabelecer conexões e informações, como uma das possibilidades para criar condições e alternativas que instigam os alunos a terem concepções e 
posturas cidadãs, cientes de suas responsabilidades e, sobretudo, perceberem-se como integrantes do meio ambiente

Ao verificar a frequência em que os assuntos relacionados a Educação Ambiental são trabalhados na escola, percebeu-se que $48 \%$ dos alunos afirmaram que ocorrem ocasionalmente, em quanto $44 \%$ afirmaram que eles sempre são trabalhados. Não corroborando com o estudo realizado por Baum; Povaluk (2012) onde 52\% dos alunos que participaram da pesquisa afirmaram que a Educação Ambiental é trabalhada o ano todo pelos docentes, e todos pontificaram que é importante que o tema seja trabalhado em sua escola.

Ao verificar em quais disciplinas a Educação Ambiental é trabalhada na instituição de ensino, destaca-se que das apontadas pelos entrevistados, $55 \%$ correspondem à Ciências, $40 \%$ Geografia e 5\% representaram as outras disciplinas. Dessa forma, conforme Morales et al., (2010), a interdisciplinaridade na formação de educadores ambientais, constitui prática pedagógica que propicia a superação da linearidade e da artificializarão no processo de produção do conhecimento e no processo educativo. Para esses autores, a interdisciplinaridade compõe uma dinâmica pedagógica aberta, dialética e reflexiva na inclusão de questões ambientais e multiculturais a fim de valorizar as diferenças e o diálogo de saberes no processo educativo.

Ao analisar o interesse dos entrevistados pelos assuntos relacionados ao Meio Ambiente averiguou-se que $52 \%$ tem interesse razoável, $40 \%$ tem muito interesse e $8 \%$ apresentam pouco interesse (Fig. 1). De acordo com Medeiros et al., (2011) a cada dia que passa a questão ambiental tem sido considerada como um fato que precisa ser trabalhada com toda sociedade e principalmente nas escolas, pois as crianças bem informadas sobre os problemas ambientais vão ser adultas mais preocupadas com o meio ambiente, além do que elas vão ser transmissoras dos conhecimentos que obtiveram na escola sobre as questões ambientais em sua casa, família e vizinhos. 
Figura 1. Interesses dos discentes em relação a Educação Ambiental.

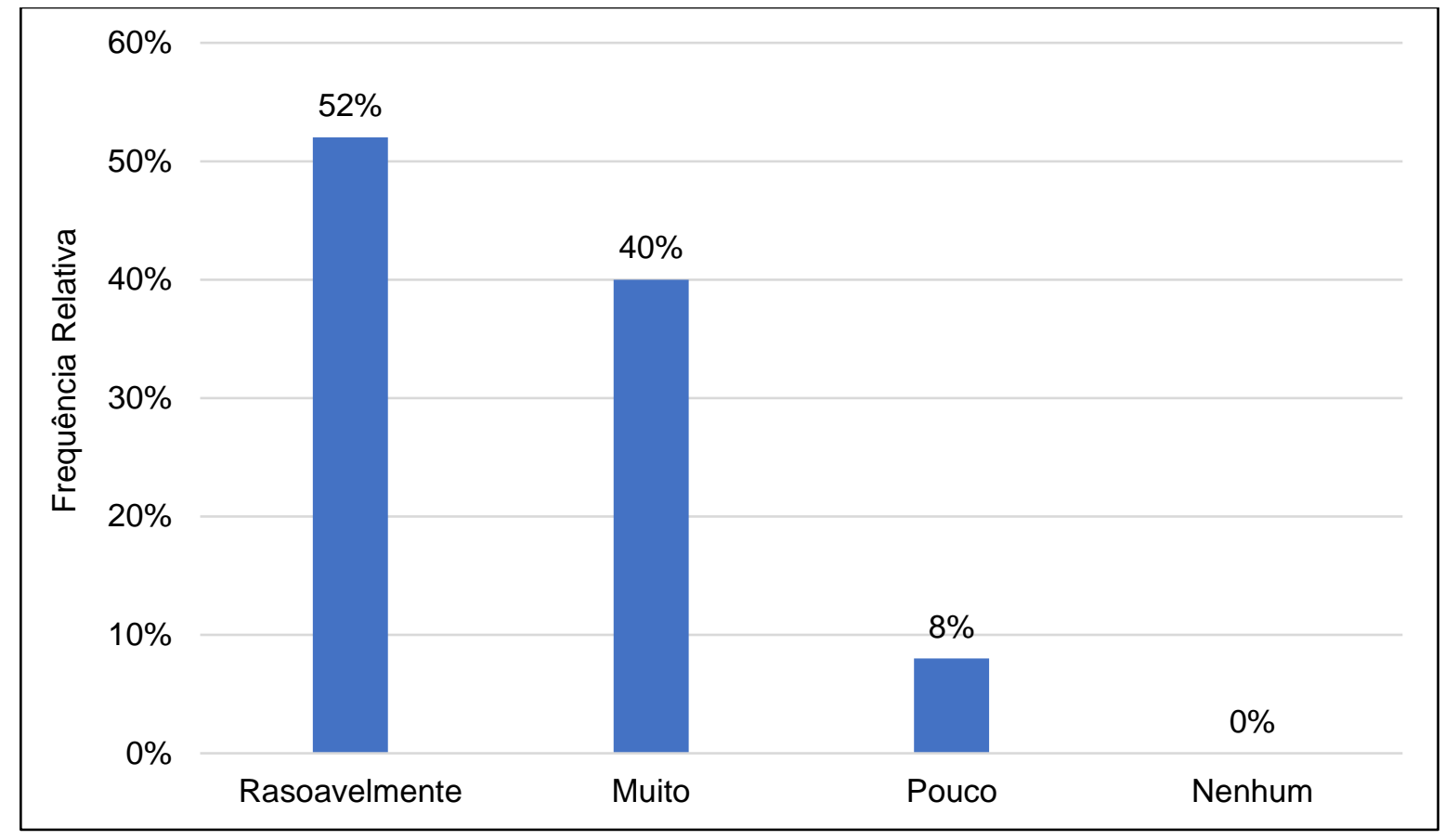

Fonte: Dados da pesquisa 2018.

Ao ponderar a percepção dos discentes acerca das soluções para os problemas ambientais na atualidade $68 \%$ afirmou que a solução está nas pequenas ações cotidianas. Corroborando com Fonseca et al., (2005) os quais constataram em seu trabalho que a responsabilidade de proteger o meio ambiente, apontado pela maioria dos alunos (74\%), é da sociedade como um todo e para 12\%, dos órgãos governamentais. Assim sendo, a responsabilidade individual e coletiva faz-se necessária para a construção de um mundo socialmente justo e ecologicamente equilibrado.

Assim, Durham (2005) ressalta ainda, a importância do envolvimento consciente e comprometido de todos os sujeitos para concretizar as transformações que a natureza e a sociedade precisam quanto ao seu cuidado e preservação. O objetivo da Educação Ambiental é propiciar equilíbrio entre o homem e o seu meio, mas, para isso, o comportamento humano em relação ao meio ambiente precisa se dar em prol de novas atitudes e valores. Assim, a Educação Ambiental passa a se constituir em instrumento para a transformação, por representar a relação entre meio ambiente e educação. 


\section{Educação Ambiental como Estratégia de Aprendizagem}

Ao verificar a frequência em que são trabalhados projetos sobre Educação Ambiental dentro da escola, a maioria correspondente à $60 \%$ dos alunos responderam que os projetos ocorrem esporadicamente. Vale ressaltar também a afirmação dos discentes, onde destacou-se que geralmente são desenvolvidos trabalhos em sala sobre a temática.

Corroborando com Medeiros et al., (2011), ao ressaltarem que projetos de educação ambiental nas escolas contribui para a formação de cidadãos conscientes, aptos para decidirem e atuarem na realidade socioambiental de um modo comprometido com a vida, com o bemestar de cada um e da sociedade. Para isso, é importante que, mais do que informações e conceitos, a escola se disponha a trabalhar com atitudes, com formação de valores e com mais ações práticas do que teóricas para que o aluno possa aprender a amar, respeitar e praticar ações voltadas à conservação ambiental.

Uma quantidade significativa dos entrevistados vê as questões ambientais como um fator importantíssimo na atualidade. E muitos destacaram que a poluição e o desmatamento são os principais fatores responsáveis pelos problemas ambientais na atualidade, sendo o ser humano o maior responsável por ações relacionadas a esses fatores.

Dessa forma, Cavalcanti-Neto \& Amaral (2011), enfatizam que é nesse contexto onde se justificam os movimentos para uma Educação Ambiental, evidenciando-se características que possibilitam problematizar a ação humana e as consequências trazidas ao ambiente pelos processos sociais, buscando-se levar as pessoas a pensarem que os recursos naturais não são infinitos. Isso pode contribuir para uma reflexão sobre o modelo civilizatório que vem sendo historicamente estabelecido e também pode nos ajudar a pensar em novas possibilidades de organização da vida no planeta.

Ainda nesse viés, Cardoso (2011) ressalta que Educação Ambiental representa um meio de motivar e promover a sensibilização dos indivíduos para que estes atuem enquanto cidadãos capazes de transformar a sociedade em que habitamos consolidando propostas que visem à preservação ambiental, visto que ao tomar decisões de forma adequada busca-se a mudança de um estilo de vida baseado no uso exagerado de bens de consumo para um estilo sob a ótica ecológica de sustentabilidade promovendo a modificação da relação do homem com a natureza.

Ao verificar o meio pelo qual os entrevistados obtêm informações sobre o Meio Ambiente, 50\% apontam ser a Televisão, 30\% afirmam ser a sala de aula, 17\% afirmam ser 
pela internet e $5 \%$ através de livros e revistas. Corroborando com o resultado identificado por Fonseca; Costa; Costa, (2005), onde em seu trabalho destacaram que quanto à busca de informações atualizadas sobre questões ambientais, a televisão foi apontada como veículo mais utilizado pelo grupo de estudo.

Alguns entrevistados apontam que poderiam desenvolver mais trabalhos relacionados à temática, onde destacaram que poderiam ser desenvolvidas ações da gestão escolar, juntamente com a participação da comunidade estudantil e realizarem como, por exemplo: o plantio de mudas de árvores. Enfatizaram também que necessitam ser desenvolvidos trabalhos de pesquisa na cidade, com o propósito de entender as ações das pessoas que a habitam.

Os alunos sugeriram que deveria haver uma disciplina relacionada a Educação Ambiental, desse modo, Santos (2007) enfatiza que uma maneira que pode ser utilizada para o estudo dos problemas relacionados ao meio ambiente é através de uma disciplina específica a ser introduzida nos currículos das Escolas, podendo assim alcançar a mudança de comportamento de um grande número de alunos, tornando-os influentes na defesa do meio ambiente para que se tornem ecologicamente equilibrados e saudáveis. Porém, estes projetos precisam ter uma proposta de aplicação, tratando de um tema específico de interesse dos alunos, e não longe da proposta pedagógica da escola.

Menghini (2005), destaca que as escolas se utilizam de trabalhos em sua maioria tradicionais, desenvolvendo um ensino de simples passagem de conhecimento, um ensino teórico e distante da prática, com pouca compreensão e envolvimento com a realidade do aluno, deixando de lado a inter-relação e a percepção do indivíduo em relação ao meio ambiente.

Ademais, trabalhar com a Educação Ambiental significa pensar num futuro melhor para nosso mundo e para as pessoas que nele habitam, colocando em prática uma ação transformadora das nossas consciências e de nossa qualidade de vida (DIAS, 2016).

\section{Considerações Finais}

Portanto constatou-se que a Educação Ambiental é consideravelmente trabalhada com os discentes relacionados à presente pesquisa, porém o interesse pelo assunto ainda é considerado razoável, visto que a metodologia aplicada para com estes não estimula-os a prática de ações no meio ambiente, à realidade em que vivem. 


\section{Referências}

ANDRADE, D. F. Implementação da Educação Ambiental em escolas: uma Reflexão. In: Fundação Universidade Federal do Rio Grande. Revista Eletrônica do Mestrado em Educação Ambiental, 2000, v. 4.out/nov/dez.

ARNSTEIN, S. R. Uma escada da participação cidadã. Revista da Associação Brasileira para o Fortalecimento da Participação - Participe, Porto Alegre/Santa Cruz do Sul, 2002, v. 2, n. 2, p. 4-13.

BARBOSA, M. L. G. Educação Ambiental: Escola e a Construção Do Sujeito Ecológico. Educação ambiental: ensino, formação e práticas educativas. Teresina: EDUFPI, 2016. 143 p.

BARCELOS, V. H. L. A questão ambiental e a educação: um diálogo necessário. Revista do Centro de Educação, Santa Maria, 1996, v. 21, n. 1, p. 5-21.

BAUM, M.; POVALUK, M. A Educação Ambiental nas Escolas Públicas Municipais de Rio Negrinho - SC. Saúde Meio Ambient. 2012, v. 1, n. 1, jun.

BRASIL, Constituição da República Federativa do Brasil, Brasília 1988.

BRASIL, Política Nacional de Educação Ambiental. Lei No 9.795, De 27 de Abril de 1999. Disponível em: < http://www.planalto.gov.br/ccivil_03/leis/L9795.htm >. Acesso em: 10 agosto 2018.

BRASIL. Ministério do Meio Ambiente. Educação ambiental: curso básico à distância. Brasília, DF: 2001.

BRASIL. Secretaria do Meio Ambiente. Conceitos para se fazer Educação Ambiental. $2^{\circ}$ ed. São Paulo: Secretaria do Meio Ambiente, 1997.

BRITTO JÚNIOR, Á. F.; FERES JÚNIOR, N. A utilização da técnica da entrevista em trabalhos científicos. Evidência, Araxá, v. 7, n. 7, p. 237-250, 2011.

CARDOSO, K. M. M. Educação Ambiental nas escolas. Consórcio Setentrional de Educação a Distância de Brasília. Brasília/DF. 2011.

CARDOSO, K. M. M. Educação Ambiental nas escolas. Consórcio Setentrional de Educação a Distância de Brasília. Brasília/DF, 2011.

CARVALHO, I. C. M. Educação ambiental: a formação do sujeito ecológico. 2. ed. São Paulo: Cortez, 2006.

CAVALCANTI NETO, A. L. G.; AMARAL, E M. R. Análise de concepções e visões de professores de ciências sobre educação ambiental. Pesquisa em Educação Ambiental. 2011, vol. 6, n. 2 - p. 119-136. 
CHALITA, G. Educação: a solução está no afeto. São Paulo: Gente, 2002.

CRUZ, J. S. Biologia: Educação Ambiental. Recife: UPE/NEAD, 2011. 64 p.

DIAS, L. S.; LEAL, A. C.; CARPI JUNIOR, S. Educação Ambiental: conceitos, metodologia e práticas - Tupã: ANAP. 2016.

DURHAM, E. 2005. Responsabilidade social nas instituições de ensino superior. Disponível em: $\quad$ www.abmes.org.br/dowland/associados/publicacoes/revista_estudos/34/estudos 34.pdf.abril2005> acesso em: 12 setembro 2017.

FARNESI, C. C. A realidade da Educação Ambiental nas escolas públicas e privadas de Uberlândia: o trabalho dos professores. Monografia de Bacharelado em Ciências Biológicas, Universidade Federal de Uberlândia. Uberlândia, 1999.

FONSECA, V. L. B.; COSTA, M. F. B.; COSTA, M. A. F. Educação Ambiental no Ensino Médio: Mito ou Realidade. Rev. eletrônica Mestr. Educ. Ambient. 2005. ISSN 1517-1256 Volume 15.

FONSECA, V. L. B., COSTA, M. F. B., COSTA, M. A. F. Educação Ambiental no Ensino Médio: Mito ou Realidade. Revista Eletrônica Mestrado Educação AmbientaI, SSN 15171256, Volume 15, julho a dezembro de 2005.

GUIMARÃES, M. Educação ambiental: No consenso um embate? Capinas São Paulo: Papirus (Coleção Papirus Educação). 2000.

IBGE (Instituto Brasileiro de Geografia e Estatística). Área territorial- cidades. Disponível em: <http://.ibge.com.br/cidadesat/topwindow.htm?.> Acesso em: 21 agosto de 2018.

JACOBI, P. R. Meio ambiente urbano e sustentabilidade: alguns elementos para a reflexão. In: CAVALCANTE, C. (Org.). Meio ambiente, desenvolvimento sustentável e políticas públicas. SP: Cortez, 2005.

JACOBI, P. R.; TRISTÃO, M.; FRANCO, M. I. G. C. A Função Social da Educação Ambiental nas Práticas Colaborativas: Participação e Engajamento. Cad. Cedes, Campinas, 2009, vol. 29, n. 77, p. 63-79, jan./abr.

JARDIM, D. B. Educação Ambiental: trajetórias, fundamentos e identidades. Rev. eletrônica Mestr. Educ. Ambient. 2009, ISSN 1517-1256, v. 22, janeiro a julho.

LIMA, W. Aprendizagem e classificação social: um desafio aos conceitos. Fórum Crítico da Educação: Revista do ISEP/Programa de Mestrado em Ciências Pedagógicas. 2004, v. 3, n. 1 , out.

MEDEIROS, A. B.; MENDONÇA, M. J. S. L.; SOUSA, G. L.; OLIVEIRA, I. P. A. 2011. Importância da educação ambiental na escola nas séries iniciais. Rev. Faculdade Montes Belos, 2011. v. 4, n. 1. 
MEDEIROS, A. B.; MENDONÇA, M. J. S. L.; SOUSA, G. L.; OLIVEIRA, I. P. A Importância da educação ambiental na escola nas séries iniciais. Revista Faculdade Montes Belos, v. 4, n. 1, setembro. 2011.

MEDEIROS, M. C. S., RIBEIRO, M. C. M. \& FERREIRA, C. M. A. 2011. Meio ambiente e educação ambiental nas escolas públicas. In: Âmbito Jurídico, Rio Grande, XIV, n. 92, set 2011. Disponível em: $\quad$ http://www.ambito juridico.com.br/site/index.php?artigo_id=10267\&n_link=revista_artigos_leitura $>$. Acesso em 13 agosto 2017.

MEDINA, N. M. Educação Ambiental para a sustentabilidade. Anais do I Congresso Internacional de Educação do Colégio Coração de Jesus, Educar uma perspectiva humanística. Florianópolis, junho, 1998.

MENGHINI, F. B. As trilhas interpretativas como recurso pedagógico. Dissertação (Mestrado) - Universidade do Vale do Itajaí, 2005.

MORALES, A. G. M. Processo de institucionalização da educação ambiental: tendências, correntes e concepções. Pesquisa em Educação Ambiental, v. 4, n. 1, p. 159-175, 2009.

MORALES, A. G. M.; LIMA, J. E. S.; KNECHTEL, M. R.; CARNEIRO, S. M. M.; NOGUEIRA V. 2010. Educação Ambiental e Multiculturalismo: Reflexões para a Formação de Educadores. Práxis Educativa, Ponta Grossa, 2010, v.5, n.1, p. 31-38, jan.-jun.

REIS, M. F. T.; TALAMONI, J. L. B.; RUIZ, S. S.; RUIZ, J. P.; TEIXEIRA, L. A.; CASSINI, L. F.; FESTOZO, M. B.; JANKE, N.; MAIA, J. S. S.; SANTOS, H. M. S.; CRUZ, L. G.; MUNHOZ, R. H. A educação ambiental na escola básica: diretrizes para a divulgação dos conhecimentos científicos. Pesquisa em Educação Ambiental, 2012, vol. 7, n. 1, p. 29-48.

SANTOS, E. T. A. Educação ambiental na escola: conscientização da necessidade de proteção da camada de ozônio. Universidade Federal de Santa Maria, Pós-Graduação em Educação Ambiental. 2007.

\section{Como citar este artigo (Formato ABNT):}

VIANA, Elaine Cristina da Silva; OLIVEIRA JÚNIOR, Geraldo Martins de; SOBRAL, Elayne Cristina Luz Menezes Novaes Cecílio; SOBRAL, Stevens Emanuel Cecílio; LIMA; Otoniel Moreira Leite. A Educação Ambiental nos anos Iniciais do Ensino Fundamental. Id on Line Rev.Mult. Psic., 2019, vol.13, n.44, p. 620-634. ISSN: 1981-1179.

Recebido: 30/01/2019

Aceito 14/02/2019 


\section{Entrevista estruturada realizada com alunos do Ensino Fundamental.}

\begin{tabular}{|lc|}
\hline Idade: \\
\hline Sexo: ( ) Masculino & ( ) Feminino \\
\hline Reside: Zona Rural ( ) & Zona Urbana ( ) \\
\hline
\end{tabular}

1. Você sabe o que é Educação Ambiental? Sim ( ) Não ( )

2. Com que frequência assuntos relacionados a Educação Ambiental são trabalhados? E onde? Sempre ( ) Ocasionalmente ( ) Nunca ( ) Não sei ( ) Sala ( ) Escola( )

3. Em quais disciplinas é trabalhado a Educação Ambiental?

4. Defina seu interesse pelos assuntos relacionados ao Meio Ambiente?

( ) Muito interessado (a)

( ) Razoavelmente interessado (a)

( ) Pouco interessado (a)

( ) Nenhum interesse

5 . Na sua percepção a solução dos problemas ambientais depende mais?

( ) Das pequenas ações cotidianas

( ) Das decisões dos governos e das grandes empresas

( ) Não sei

6. São trabalhados projetos sobre Educação Ambiental dentro da escola?

( ) Sim, frequentemente ( ) Sim, Ocasionalmente ( ) Nunca ( ) Não sei

7. Como você vê as questões ambientais na atualidade?

8. Como são desenvolvidas as práticas relacionas a Educação Ambiental?

9. Como você obtém informações sobre o Meio Ambiente?

( ) TV ( ) Internet ( ) Sala de aula ( ) Livro e revistas ( ) Outros

10. Na sua opinião, como deveria ser trabalhada a Educação Ambiental na escola? 